\title{
INVESTIGATING LEARNING SPACE FOR RESEARCH WORKSPACES IN HIGHER EDUCATION IN MALAYSIA
}

\author{
${ }^{1}$ Norhafezah Yusof, ${ }^{2}$ Rosna Awang Hashim \& ${ }^{3}$ Chan Kok Kian \\ ${ }^{1}$ School of Multimedia Technology and Communication \\ ${ }^{2 \& 3}$ School of Education and Modern Languages \\ Universiti Utara Malaysia, Malaysia

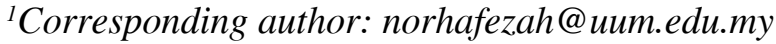

\begin{abstract}
Purpose - The purpose of this paper is to investigate learning space for research workspaces in Higher Education Institutions (HEIs) in Malaysia based on the evaluations by experts and university research workers on a practical model for creating an effective research learning space. It examines expert analyses of the notion of a suitable research learning workspace and explores worker viewpoints on this issue.
\end{abstract}

Method - Experts from business $(\mathrm{n}=2)$, education $(\mathrm{n}=2)$ and architectural $(n=2)$ backgrounds were interviewed and a survey was conducted on research workers from selected universities in Malaysia $(n=222)$.

Findings - A research learning workspace model is proposed based on evaluations by workers and experts on what was needed in a research-based working space to make it more work-friendly and intellectually stimulating for researchers.

Significance - This research attempts to understand research learning space problems in institutions of higher learning and proposes one possible model for future research learning workspace planning. It also contributes to the literature on research learning workspace and its management in developing countries, especially when Asia is positioning itself today as a competitive global educational hub.

Keywords: Higher Education, research, learning space. 


\section{INTRODUCTION}

Research learning spaces are vital to HEIs due to the contribution of research output to the ranking, reputation and development of universities. Studies on research learning spaces have traditionally focused on facilities (SCHEV, 2004; Hebert, 2012; Kärna \& Julin, 2015), business metrics (Unwin et al., 2008) and business models (Rytkonen \& Nenonen, 2014; Rytkonen, 2015). In the context of HEIs, learning spaces faced challenges in terms of the ability to change or adapt in order to meet the student need for flexible learning spaces that would enhance contemporary learning activities (McLaughlin \& Faulkner, 2012; Becker et al., 2015). There are few significant space-related studies in Asia, for example in Malaysia, where Elyna and Pitt, (2014) have discussed aspects of space management. Elyna and Pitt (2014) provided an overview of the development of facilities management in Malaysia. They found that facilities could be categorized according to seven main factors, namely level of growth, practice, service, profession, opportunities, demands and challenges. This study has provided a point of departure as it has pointed to several potential areas to be studied in Malaysia.

Research and development has been one of the most prominent sectors contributing to the Malaysian economy. In the Ninth Malaysian Plan, the government had allocated USD 1,434.5 million to this particular sector (Economic Planning Unit, 2009). In the 10th Malaysian Plan, the allocation increased by 40 percent in this sector (Economic Planning Unit, 2010). The government has invested 12 percent of this allocation to improve the quality of the nation's public universities which it is hoped will, in turn improve the national and global rankings of the public HEIs. Furthermore, the Ministry of Higher Education has introduced clusters of universities ranging from APEX (Accelerated Programme for Excellence) universities, Research universities and General universities based on the Malaysian University ranking system report (Bernama, 2008). To boost research and development in these universities, the first step taken was to provide the best facilities for university researchers, including providing a vibrant physical research learning workspace. In 2014, USD 14.9 billion was invested on education, which accounted for 21 percent of the total national budget (Budget 
Speech, 2014). In the 11th Malaysia Plan, the government continues to support the public universities in their efforts to enhance the standards of tertiary education in Malaysia (Economic Planning Unit, 2015).

In the context of Higher Education (HE), studies on research spaces are embedded in learning spaces. No distinction was made between the two areas, i.e., learning space and research space when studies examined both areas concurrently (Oblinger, 2006; Becker, Van der Voordt \& Dewulf, 2015). This phenomenon is not uncommon as both spaces co-exist in the HE environment. Both are seen as playing important roles in the sustainability of Higher Education Institutions (HEIs). A long tradition of research learning space on HE spaces has focused on ensuring that learning and research spaces adhere to the clients' needs, i.e., students, academics and administrators (Oblinger, 2006; Rytkonen, Nenonen, Ôsterlund \& Kojo, 2015). However, most of the related research came from the developed countries such as the United Kingdom (UK) and the United States (US) (ClementsCroome, 2006; Harrison \& Cairns, 2008) where HEIs are considered as popular destinations for overseas students, bringing financial stability to the respective universities. Since culture and contexts do influence research workspace learning, there is a need to add data from the East to the existing literature, especially when in recent years, HEIs in Asia are gaining prominence. This study focuses on research workspace learning in the context of HEIs in Malaysia as there is limited empirical information on this specific context from an Asian perspective, more specifically from a Malaysian perspective. Previous studies on research learning workspaces and space-related research as mentioned above have focused on different aspects of research learning workspace models and space management issues. However, they do not address the issue of research learning space in HEIs. Thus, this study presents an alternative understanding of the research learning workspace from the perspectives of research workers and experts in HEIs environment.

For the last thirty years, research on the workspace has focused on seemingly disparate ideas of aesthetic, instrumental and symbolic roles of spaces in organizations (Elsbach \& Pratt, 2007). Currently, the trend has been towards integrating the above three dimensions 
to prepare an ideal physical space for employees. However, this effort is still insufficient in terms of its contribution of knowledge to the area of research learning workspace (Davis et al., 2011). In the present study, the aim was to investigate from the perspectives of research workers and analyses of experts the research learning workspaces in local HEIs and to propose a working model for the research learning workspace. It must be borne in mind, however, that the proposed model of research learning workspace in this study refers to only one possible model for working in a research learning space. The model explores the suitability of the research learning workspace in terms of the preference expressed by the research subjects. This attempt is driven by the need to complement parameters often studied in extant workspace research. For example, there is a call from Elsbach and Pratt (2007) for Asian researchers studying workspaces to fill a gap in the field, which is to look at both the physical and social environments previously ignored.

\section{LITERATURE REVIEW}

Studies on research learning spaces have in the past, been focused on the physical (Cole et al., 2014), psychological (Oblinger, 2006) and, business (Rytkonen, 2015) aspects. Cognizant of the need to consider the importance of integration in research learning space study, the authors have covered three main themes that could provide a more holistic approach in the design of research learning space. They were 1) economic and social perspectives, 2) communication perspective and 3) research learning spaces. These themes constitute important elements in research on the development of research learning space models.

In the Massachusetts Institute of Technology (MIT), scholars have expressed concerns with the relationship between the research learning workspace environment and cost benefits (Harrison \& Cairns, 2008). Although, architects and engineers are able to build buildings with a modern design, there is a growing concern with how occupants cope with the workspaces in their organizations. Previous researches have shown that in constructing research learning space, the human aspect is an important variable (Rickards et al., 2015). 
Researches on high-tech spaces also encountered the same dilemma when it was found that people's needs and their organizations' workspace plans were in conflict (Weiss \& Schoenberger, 2015). Mohamad Tajuddin (2008) emphasized the point made in Jencks and Kropf (2006) whereby the researchers' communication theory analytical framework underpinned the need to take into account building spaces, culture and tradition. This is because the occupants are the ones who will use the spaces and not the builders or the architects of the buildings. Therefore, it is important to consider the many cultural factors that may vary from one place to another.

\section{Research Learning Space}

Research learning spaces in HEIs needs to adapt to changes. Oblinger (2006) presented data to show how research learning spaces that could offer client-centered needs in the HEIs would increase the satisfaction of students and enhanced staff performance. Work by Clements-Croome (2006) and Harrison and Cairns (2008) gave support to the idea of investing in physical, psychological and technological aspects of a building since a research learning space could attract financial rewards for HEIs in the UK and the US.

Hebert's (2012) research on the US national laboratory site suggested that researchers need to be well informed via communication protocols during the relocation of lab spaces. Failure to do so may invite ambiguity that can lead to disruption to research progress and outcomes. As experts, researchers' needs have to be fulfilled; such as provision of the latest equipment to ensure satisfaction in work and continuity in excellent outcomes (SCHEV, 2004; Kärna \& Julin, 2015). Business metrics of space utilization in labs are developed to measure the performances of the research spaces (Unwin et al., 2008). In contrast to conventional occupancy-based metrics of space utilization, the business metrics have enabled the management to assess the efficiency of space asset with expected outcomes of the research and track the usability of the research spaces. The Business model is another concept to assess space utilization efficiency (Rytkonen \& Nenonen, 2014; Rytkonen, 2015). Using five business model lenses, namely offering, customers, revenue streams, resources and cost structure, the model could offer a holistic guide 
in managing spatial development projects in universities. It is also contextual and thus, the model needs to be applied with caution as it may differ from one context to another (Rytkonen, 2015).

Early work on a research learning workspace model in higher education was championed by DEGW (Duffy Eley Giffone Worthington) through various initiatives in universities in the United Kingdom (Neary et al., 2010). While many scholars had discussed issues on research learning space models in higher education, little was done in terms of coming up with practical research learning workspace models for the higher education context.

According to its website, DEGW is a global consultancy focused on the changing nature of work and its impact on people, places, and performance. As a design company that was pioneering innovative designs in the learning-based workspace, it tapped into the combination of expertise drawn from architects, engineers and design experts. Today, the company has evolved to become Strategy Plus, a strategic business practice within AECOM (Wilding, 2012). DEGW (2006; 2009), has proposed five main learning workspace models which are suitable for HEIs, namely 1) studies, 2) quarters, 3 ) clusters, 4) hubs and 5) clubs. The models could be described as follows:

1) Studies: The concept of this model is to provide small work rooms to help individuals pay more attention on their work, including a central zone used for informal and social interactions, meeting spaces and common facilities,

2) Quarters: The setting in this model is more towards supporting individual work in a group. It is a familial workspace area,

3) Cluster: This model refers to a cluster which is semi-open, has a flexible workspace which enhances collaborative working between small- to medium-sized groups of staff, and encourages interaction and mix amongst the users of the space, such as the staff, students and visitors,

4) Hub: It is an open plan workspace with a substantial provision of shared work areas, collaborative and social settings, and

5) Club: This model provides a range of work settings for use in an activity-based way. 
Economic and Social Perspectives

Recent and future buildings require societal friendly structures and usages (Duffy et al., 2011; Hajdukiewicz et al., 2015). Most owners of office buildings are aware of the need to provide security and serendipity which will provide economic and social sustainability (Duffy et al., 2011; Hajdukiewicz et al., 2015). The question of building a new building now is no longer about its height but its aesthetic and pragmatic values to the users.

Due to the importance of space learning studies, the MIT has introduced a space and communication course at the postgraduate level. There is ample evidence that learning space has gained important recognition as there is a close relationship between people feeling at ease and their performance at the workplace. Moreover, according to Tom Allen, an MIT Professor (1997), communication mapping can be done from research learning spaces in order to analyze how team works and how individuals expand their communication network during the working period. It is apparent that learning workspace research supports healthy working environments, cuts cost and eventually increases job performances in organizations. Usually, the design of the learning workplace adopts a conservative framework rather than prioritizing the strategic needs of the organization, such as a user-friendly atmosphere and cost-effective design (Hassanain, 2006). Moreover, research shows that a flexible working environment and a chic or modern office design may also be highly effective for attraction and retention (Earle, 2003, Ferm \& Jones, 2015). Thus, it is important for space designers to understand the diverse needs of the space users, especially in relation to crucial factors such as costs and user satisfaction.

In studies conducted on the learning engagement of workers in UK universities, space construction was found to be vital in ensuring the sustainability of the universities (Lizzarralde et al., 2015; DEGW, 2006). One of the studies focused on the different nature of the universities and in what way this would determine how spaces need to be constructed in HEIs (DEGW, 2006). For example, a researchbased university needs to take a different approach compared to a university that caters to undergraduate students. In the context of research-based universities, social science and science faculties have 
been debating on the extent to which the allocation of spaces needs to be considered. Universities in developed countries have been conscious in offering the best research learning space facilities for users as the facilities could attract the best students and researchers to their universities. Interestingly, studies on the science of spaces in Asia have not been vigorously developed, perhaps due to budget constraints.

In the context of a business organization, Ilona Kojo and Nenonen (2015) stated that a workspace needs to conform to the coreperiphery workforce model, which is able to offer a conducive working environment. Studies on multi-national corporations on space construction indicate that workers need to be satisfied in their working spaces (DEGW, 2009). For example, companies like the $\mathrm{BBC}$ and Google believe that to retain their knowledge workers, the workplaces need to be designed with a comfortable work setting, open spaces, and a clean environment and stress-free atmosphere (DEGW, 2009). These companies' effort in emphasizing the importance of space underpins their strong belief that an efficient office space will provide positive motivation to the workers.

\section{Communication perspective}

Research has shown that an open-office environment provides ease and frequency of use and this in turn, promotes the rearrangement of workgroups (Diesenhouse, 2001) as it encourages spontaneous interactions among employees (Seddigh et al., 2015). Behaviors such as small group interaction, friendship formation, participation, aggression, withdrawal and helping, have been shown to be influenced by environmental conditions. Groups of open office enthusiasts argue that the environment facilitates interaction among employees and increases communication by removing physical barriers, such as walls (May et al., 2005).

Earle (2003) and Heerwagen et al., (2004) defined that a building might be able to add value to knowledge sharing by providing a surface/building layout that promoted interaction between employees and therefore, enhanced awareness of each other. Davenport (2005) has observed that high-performing knowledge workers have a high 
level of collaboration as a part of their work style, and that they will be most effective when the space is designed to foster collaboration. Compared to cellular offices, a more open environment is often associated with decreased psychological privacy and increased noise and disturbance (Parkin, et al., 2011). At the same time, they are also associated with productivity, motivation and a decline in job satisfaction. To strike a balance between the need to provide privacy and the promotion of interaction and knowledge flows, it is essential to provide a variety of settings in the activities of the office environment, affording occupants access to both the dynamic and private working space environment (Duffy, 1997; Worthington, 2006). In the context of HEIs, the custom and design of space is a theme that has come to the forefront of the educator's interest in the past few years, particularly as competition to attract student enrolments and later retaining them in the universities (Bryony, 2011).

The key component in communication aspects are interaction flow and space identity which will eventually lead to the productivity and prestige of the organization. In terms of interaction flow, there is the argument of privacy and social interaction. Studies have shown that employees need privacy to focus on their work, but at the same time pursue interaction among co-workers as part of an essential socialization process such as mentoring (Neary et al., 2010).

\section{METHODOLOGY}

The present empirical research used a survey and interviews to gather data. The target respondents of the survey questionnaire included all research workers from three selected universities. The three universities representing the category of universities in Malaysia mentioned earlier were selected based on their intensity in research activities. For interviews, the experts were selected based on their involvement in education-based experiences

\section{Participants}

For the survey method, the total respondents were 222 research workers. Target respondents were selected based on their direct 
hands-on involvement with research projects. These respondents were requested to identify their preferred research workspace model. Survey questionnaires were sent to 200 target respondents in an Apex university, 100 target respondents in a Research university and 80 target respondents in a General university. A total of 115 completed questionnaires from the Apex university, 53 from the Research university and 54 from the General university were returned, representing a response rate of 58 percent, 53 percent and 68 percent, respectively.

For the interview, two male and four female experts were invited. The experts were given pseudonyms for purposes of maintaining anonymity and confidentiality. Both the males were business experts with more than 30 years of experience in business management. Expert A had the following academic qualification, an Advanced Diploma and Expert B was a PhD holder. The educational experts were females; both held a $\mathrm{PhD}$ and had more than 22 years of experience in educational management (Expert $\mathrm{C}$ and D). Experts in architecture were represented by a female and a male. Both had degrees in Architecture and had been in the field for more than 20 years (Experts $\mathrm{E}$ and $\mathrm{F})$. In sum, they were experts in business $(\mathrm{n}=2)$, education $(n=2)$ and architecture $(n=2)$. The criteria of selection were:

1) conceptualizing and managing learning based space for business experts

2) leading their institutions in managing learning space for education experts

3) designing and maintaining learning based space for architecture experts

\section{Research Tools and Analysis}

The study employed a survey instrument and interviews as data collection tools. The survey instrument was adapted from the DEGW (2009) work on research workspace models. In order to facilitate participant response, each model was presented in diagram form to give the respondents a visual image of the different learning spaces. They were asked to choose an ideal model based on the five models that were shown to them. The respondents were requested to rate 
their model preference in terms of a 5-point Likert scale. For the details, please refer to Appendix A.

For the expert interview, an interview protocol was developed based on the related literature and they were presented to the experts before the interview. The protocol was verified by an expert from education, business, and architecture. These experts had been in their respective fields for more than eight years. Both the education and business experts were university lecturers and the architect was a consultant in developing educational institutions. The protocol was revised based on the feedback of experts in space and management before it was distributed to the interviewees. The experts were briefed on the purpose of the study and the procedure of investigation. They gave their informed perspective on best practices in terms of research workspace designs.

The interview protocol had four main dimensions, namely (1) personal background, (2) economic perspective on space, (3) social aspect on space (4) communication perspective on space. The interview focused on factors that contribute to research space development and sustainability. The focused dimensions were economic, social and communication perspectives. Each interview lasted for 30 - 60 minutes. Most interviews were conducted at the offices of the respondents and were tape-recorded with their permission. The researchers sought to clarify any discrepancy regarding the interviews by contacting the respondents via face to face meetings, text messages and phone calls. This helped in establishing the credibility of the study. Data were analyzed using the framework in Braun and Clarke (2006), which comprised a system of coding and categorization that underpinned the analytical approach. The researchers read and coded the data to ensure familiarity with the data and the development of key phrases were based on the four identified dimensions. A sample of questions included: "Would you please kindly tell us about your professional background", "What is your view on the economic perspective on space usage?", "How about the social aspect of space in a research learning workspace", and "What kind of design will stimulate communication activities in the workplace?". 


\section{FINDINGS}

\section{Demographics}

A total of 222 respondents, representing a wide range of research workers, completed and returned the questionnaires. Research workers here referred to those who were involved in research work. The majority indicated that they were working at the universities, i.e., full time staff ( $n=141,63.51$ percent); while some were studying, i.e., full time postgraduate students ( $n=73,32.88$ percent), and a few were studying and working, i.e., part time postgraduate students who had a full time job ( $\mathrm{n}=8,3.60$ percent). A large majority of the respondents were female $(\mathrm{n}=135,60.8$ percent), while fewer ( $\mathrm{n}$ $=87,39.2$ percent) were male. Most of the respondents indicated that they were between 21-29 years old ( $n=123,55.4$ percent), next were the groups aged between $30-39$ years old ( $\mathrm{n}=56,25.2$ percent), then groups aged $40-49$ years old $(n=24,10.8$ percent) and the last group were those aged 50 and above $(n=19,8.6$ percent).

In terms of the research workspace model, almost the majority of respondents ( $n=107,48.2$ percent) from the three universities found model five (club) attractive.

\section{Experts view on space management}

Four main themes emerged from the interview analysis: 1) spatial needs, 2) specific needs, 3) idea on change and 4) elements in workplace design.

\section{Spatial needs}

The experts agreed that the spatiality needs of the users need to be addressed. The needs identified were smartly designed work, health friendly and safe workplaces. Smartly designed work referred to the flexibility of provided spaces to cater to the specific needs of the users. For example, as was elaborated by education expert F (all transcribed views below are presented without any editorial corrections):

Well, in research work, we have different kinds of needs of people that we need to cater. These individuals need 
space for concentration and space for group discussion due to their nature of works. A smartly designed work space could be able to cater for those needs.

Indeed, this standpoint was supported by business expert A. According to the expert, in light of financial matters, planners and users need to optimize the use of space in the workplace: A place where it is sufficient for working purpose, where staff can work and rest. Moreover, smartly designed work also was related to providing health friendly space to the space users. As highlighted by business expert B, an established and smart management team would prefer to provide health friendly working spaces for employees and clients. This was because the elements of 'healthy and safe workplaces' will bring more positive outcomes to the employees, such as enhancing job motivation and job satisfaction in the long run. In terms of safety, education expert D stated that:

It is pertinent to state about spatial safety here. Safety is vital so that the users feel safe in doing their work in the workspace. The spaces need to be comfortable. Thus due to our climate change, facilities such as airconditioning need to be there to provide the comfort for working.

Spatial needs offer a flexible arrangement of space that could cater to the personal and professional nature of individuals who were involved in research activities.

\section{Specific needs}

Another issue was the specific/extra needs that were addressed by the experts. From their viewpoints, they argued that there were special and extra needs which the planners needed to fulfill in order to provide the best working space environment for the users. The needs were the latest communication and network facilities, ergonomic furniture and user-friendly storage. When the experts dealt with specific needs, their concern was how the users, i.e., the research worker could benefit the most when they used the research space. For example, architecture expert F: 
Specific needs for working spaces are printing / Xerox machine, computers, cabinets to put sample of material, tender documents and files, etc. All of these facilities need to be installed in an office to provide conducive working environment for the users. This means employers need to think about practical storage.

The above points were also raised by education expert C:

What do we need? Hmm... in the midst of doing the work, we need the advanced communication gadgets. Thus, basic communication facilities need to be there; wifi, laptops and etc-should be supported by the research grants. Things like furniture need to have ergonomic values which will be able to stimulate thinking. There had been incidents in the past which we label as PhD Syndromes such finger numbness, back pains and nerve damages. It happened due to non-ergonomic facilities which affected the health of the graduate students in the long term.

Specific needs such as these highlighted the distinctive characters of research work spaces. Each work space needs to be equipped with the latest facilities of office utilities that could facilitate the research work.

\section{Idea on change}

On the idea of change, the experts argued that the workspaces needed to address the issue of congested spaces, lack of facilities and provision of more 'thinking spaces'. It would indeed be considered a luxury to have all the demands fulfilled. Thus, the space design needed to address the following criteria: feeling of less congestion, more breathing spaces, enough rooms for discussions and interactions and basic work and resting facilities. Thus, what this meant was that workspaces design needed to be flexible according to the needs of the users. As commented by business expert A and in line with architect expert E's view: 
Workspace sizes need to be designed according to the size and capacity of the posts. Thus, it will be comfortable for the manager, director and staff of the organization. It needs to follow the professional advice of professional architects

Education expert D emphasized the point about 'thinking space':

We need larger space. Perhaps we could sacrifice lecturers' room to put four research students in a room. And of course, we have to be gender sensitive. Researchers need silent space to study and work on their own. To add, cubicles can be introduced for study space in an institution. There is also a need for administrative space and also a place where people can pray and relax.

\subsubsection{Elements in workplace design}

Thinking space in the context of this study referred to a quiet place where the workers could concentrate on their work and eventually could be more productive in terms of performance. The space should offer the workers the opportunity to do reflection on their everyday work, either in creating new ideas or sharing ideas with other colleagues. Sensitivity towards power related positions and gender were among the interesting issues highlighted by the experts. These views on status and gender sensitivity were raised in the specific Malaysian cultural context and were seen as more collectivist and predominantly Islamic in nature . Power distance reflected the sensitivity of the collectivist culture where individuals were categorized and treated according to their status in the hierarchy. The higher the position, the more privilege was accorded to the person. In terms of gender segregation, it has been the norm in Malaysia that females and males are not encouraged to be together in an enclosed room. This practice underscores the need to uphold Islamic values in matters of male female interactions: whereby it is forbidden to have two strangers, a male and a female, who are not related by marriage or blood to be together in a closed room without the presence of other female or male friends. 
Human resources, costs and facilities are vital elements in designing workspaces. Most experts believe that planners need to consider these vital elements to ensure high performance among the users. As pointed out by architecture expert E:

Planners need to address the human needs as we need to provide comfortable environment for the users. It is also important to ensure the strategic location of each space. This is to minimize the movement in the office.

In addition, business expert $\mathrm{A}$ emphasized the significance of costs and facilities:

In this context, cost is important. Planners need to prepare the budget because each construction need detailed planning. We need to get expert's view (professional architects and interior designers) to determine the appropriate facilities planning with suitable budget.

A good workspace design demands that the fundamental needs of the users be fulfilled in a creative manner. In terms of the effective management of human resources, an institution has the privilege of managing and sustaining the movements of humans in the workplace. Less movement indicates high concentration in their research work. Furthermore, a cost effective space design could further position the institution as having a better cost-effective research space model in Malaysia. In all instances, facilities should be made readily available and be used optimally in producing the best outcome.

The abovementioned four issues addressed by the experts provided the guidelines for the use of space in the research workspace model highlighted in this study.

\section{DISCUSSION AND CONCLUSION}

The findings indicate that in investigating appropriate models of research learning space, an important priority is the careful 
consideration of the needs of the people who will occupy that space. Furthermore, the physical, social and communication needs have to be also in line with the planned budget.

Each model has its own unique appeal in terms of space distribution, use and networks. In the Club model, the respondents, i.e., users prefer the model due to its offerings of flexibility, privacy and open space for discussions (refer to Appendix B). It provides a range of work settings to be used in an activity-based way. In addition, the model delivers a variety of work settings in a non-territorial environment and the model provides the option of being wholly public or private through invited access only to its community of users. The model is good for staff who are mobile and those who often work in other locations. It can support a disparate community or network of people who come together to share knowledge. This model provides an efficient use of space for mobile workers. The challenges in this model are however, its affordance of higher mobility and autonomy. Research learning space requires ongoing management and access to storage of personal files. This model provides a balance between the requirements of functionality and sociality. The model's ability to cater to a meeting point between the two extremes, the need for privacy in the workspace where individuals can concentrate on individual activities and at the same time enjoy the space for discussions or meetings with colleagues is crucial from the viewpoints of users and experts.

In addition, a majority of the respondents agreed that each research learning workspace needs to fulfill the physical and social needs of the users. This is in line with the experts' recommendations that the workspace should be able to enhance work performance and thus, management needs to be able to attend to the specific detailed needs of staff and students in their respective workspaces. The integration of the physical and social environments in space modeling and design in the present study captures the essence of extending the parameters of concern found in previous studies on space. Most global companies like Google and BBC have invested a lot in workspace construction as they believe that when employees are happy with their workspaces, the tendency for them to perform better is higher (DEGW, 2009). 
Another interesting finding in this study is the relevance of the notion of communicative space (Jencks and Kropft, 2006) and the concept of 'generative building' (Kornberger \& Clegg, 2004) in helping one better understand the high performance workspace. Jencks and Kropft (2006) argued that in building a space, one could not isolate social interaction among the members in the space. This socialized space needs to have user-centered elements and be flexible enough to provide intra, inter and cross-organization work arrangements (Kornberger \& Clegg, 2004).

These twin principles of having both flexible and yet private spaces, support the research finding whereby workers in the study have indicated that they preferred a flexible functional workspace which at the same time provided them with a quiet place to concentrate on their work. In addition, the experts emphasized on the importance of the workspace being able to cater to fundamental needs while at the same time to be open to change, especially to be sensitive to the ongoing demands of needs in research and development.

The essence of research space of concern in this study is in the contextual setting of the HEIs. Researchers have been cautioned in generalizing empirical findings due to the uniqueness of the data gathered from various research settings (Hebert, 2012; Rytk-nen, 2015). The essence of the research space captured in this study differs from other studies due to its emphasis on exploring a suitable model of research learning workspace. Other studies on research learning spaces have contributed to the field due to their special concerns with utilities (Hebert, 2012), users' satisfaction (SCHEV, 2004; Kärna \& Julin, 2015), business metrics (Unwin et al., 2008) and business model (Rytk-nen \& Nenonen, 2014; Rytk-nen, 2015). In the context of this study, HEIs need to consider learners' various needs and cultural differences in designing spaces for learning. Since HEIs in Malaysia are embracing a student-centered approach, learner voices in designing a learning space is crucial to ensure progress in the academic or research agenda.

The club model chosen by the respondents represented the need for individual privacy and group collaboration in the work settings. The research workspace model offers a non-territorial space where 
workers can move from a privacy setting to a group setting at their convenience. It offers part-time and full time workers the flexibility to adjust accordingly in terms of space utilization. It should be clear though that the other models in the study could also be regarded as appropriate models of research workspaces, given their particular capacity to cater to the specific needs of different users. The Club Model is especially useful as it can fulfill the need for researchers to work in private with full concentration when the need arises, but at the same time be flexible enough to allow engagement with others in discussions when this is appropriate.

Interestingly, there are two issues worth highlighting based on the viewpoints of experts on space sensitivity. Firstly, the issue of power distance in space arrangement. In the space research literature, the experts have pointed out that the higher the position of the individual in the organizational hierarchy, the higher the possibility that the person will be given privileges in terms of spaces and facilities. This power-distance in collectivist culture was highlighted in the study by Hofstede et al. (2010). They described the phenomenon where privileged individuals were offered more benefits compared to the rest due to their power, positions and status in the community or institutions. Another interesting issue is about gender sensitivity, especially in the cultural context in which it is not the norm for a male and female to be together in an enclosed room. As Malaysia is practicing Islamic norms and values, it is not advisable for two strangers, who are male and female and who are not related through blood ties or marriage to be together in an enclosed physical space. Given the nature of research work that requires long hours and in view of the need to abide by these norms, the management of HEIs will have to provide more 'open' research spaces in which the female and male research workers are more at ease with each other's presence and not fear the risk of violating extant cultural norms.

The foregoing discussions of the findings should close with this caveat: the research setting is Malaysia. It is therefore, hoped that future studies will include HEIs from other Southeast Asian countries as this will certainly complement the existing data by providing new insights to the study of research space in different HEI settings. 


\section{REFERENCES}

Allen, T. (1997). Architecture and communication among product development engineers. MIT Sloan School of Management. Cambridge, MA: Working paper, 1-35. Retrieved from http: www. https://dspace.mit.edu/bitstream/handle/1721.1/2682/ SWP-Beckers, R., Van der Voordt, T., \& Dewulf , G. (2015). A conceptual framework to identifyspatial implications of new ways of learning in higher education. Facilities, 33, 2 -19 .

Bernama. (2008). UM diiktiraf university cemerlang, [UM is recognized as an excellent university]. Retrieved fromt http://www.bernama.com.

Braun, V., \& Clarke, V. (2006) Using thematic analysis in psychology. Qualitative Research in Psychology, 3, 77-101.

Bryony, R. (2011). Evaluating the impact of learning space. Reference Services Review, 39, 451-464.

Budget Speech. (2014). Budget speech by Prime Minister of Malaysia. Retrieved from http://www.bnm.gov.my/index. phd.

Clement-Croome, D. (Ed). (2006). Creating a productive workplace. London: Taylor \& Francis:

Cole, R.J., Oliver, A., \& Blaviesciunaite, A. (2014).The changing nature of workplace culture. Facilities, 32, $786-800$.

Corsten, D., \& Gruen, T. (2004). Stock-outs cause walkouts. Harvard Business, 82, 26-28.

Davenport, T. (2005). Thinking for a living: How to get better performance and results from knowledge workers. Boston, MA: Harvard Business School Press.

DEGW (2006). Design for change. Retrieved from http://www. degw.com/about.aspx.

DEGW (2009). Design for change. Retrieved from http://www. degw.com/about.aspx.

Diesenhouse, S. (2001, January). Flexible office layouts draw tenants in Boston. The New York Times, 7.

Duffy, F. (1997). The new office. London: Conran Octopus.

Duffy, F., Craig, D., \& Gillen, N. (2011). Purpose, process, place. Facilities, 29, 97- 113. 
Earle, H. A. (2003). Building a workplace of choice: using the work environment to attract and retain top talent. Journal of Facilities Management, 2, 244-257.

Economic Planning Unit (2009). Economic Planning Unit. Retrieved from http://www.epu.gov.my

Economic Planning Unit (2010). Economic Planning Unit. Retrieved from http://www.epu.gov.my

Elsbach, K. D., \& Pratt, M. G. (2007). The physical environment in organizations. The Academy of Management Annals, 1, 181-224.

Elyna, M.N., \& Pitt, M. (2014). Facilities management in Malaysia. Facilities, 32, 490 -508.

Ferm, J., \& Jones, E. (2015, February). London's industrial land: Cause for concern? Bartlett School of Planning, University College London, London.

Hajdukiewicz, M., Byrne, D., Keane, M.M., \& Goggins, J. (2015). Real time monitoring framework to investigate the environmental and structural performance of buildings. Building and Environment, 86, 1-16.

Harrison, A., \& Cairns, A. (2008). The changing academic workplace. Glasgow: DEGW UK Ltd.

Hassanain, M. A. (2006). Factors affecting the development of flexible workplace facilities. Journal of Corporate Real Estate, 8, 213 - 220.

Hassen,T-H.S., \& Solvoll, H.G. (2015). The importance of university facilities for student satisfaction at a Norwegian University. Facilities, 33, $744-759$.

Health and Safety Executive Railway Safety Principles and Guidance. (2005). Health and safety: guidance Booklets Health and Safety 153/1. Retrieved from http://products.ihs. com/cis/Doc.aspx?AuthCode $=\&$ DocNum=293512.

Hebert, P. R. (2012). In situ perceptions of a move. Journal of Facilities Management, 10, 114 - 132.

Heerwagen, J.H., Kampschroer, K., Powell, K.M., \& Loftness, V. (2004). Collaborative knowledge work environments. Building Research \& Information, 32, 510-28.

Hofstede, G., Hofstede, G. J., \& Minkov, M. (2010). Culture and organization: Software of the mind. USA: McGraw-Hill Professional. 
Ilona Kojo, I. V., \& Nenonen, S. (2015). Places for multi-locational work - opportunities for facilities management. Facilities, $33,20-37$.

Jamil, A. (2009). Ergonomik menjana keselesaan di tempat kerja [Ergonomics generate comfortable workplaces (Unpublished master's thesis), Universiti Utara Malaysia, Malaysia.

Jencks, C., \& Kropf, K. (Eds.). (2006). Theories and manifestoes of contemporary architecture. Chichester, West Sussex: WileyAcademy .

Kärnä, S., \& Julin, P. (2015). A framework for measuring student and staff satisfaction with university campus facilities. Quality Assurance in Education, 23, 47 - 66.

Kornberger, M., Stewart R., \& Clegg, S.R. (2004). Bringing space back in: Organizing the generative building. Organization Studies, 25, 1095-1114.

Lizarralde, G., Chmutina, K., \& Dainty, A. (2015). Sustainability and resilience in the built environment: The challenges of establishing a turquoise agenda in the UK. Sustainable Cities and Society, 15, 96-104.

May, D. R., Oldham, G. R., \& Rathert, C. (2005). Employee affective and behavioral reactions to the spatial density of physical work environments. Human Resource Management, 44, 21-33.

McLaughlin, P., \& Faulkner, J. (2012). Flexible spaces ... what students expect from university facilities. Journal of Facilities Management, 10, 140 - 149.

Mohamad Tajuddin, M.R. (2008). Seni bina: Sejarah, teori dan kritikan [Architecture: History, Theory and Critics], UTM, Johor, Malaysia: UTM Press.

Ndirangu, M., \& Udoto, M.O. (2011). Quality of learning facilities and learning environment. Quality Assurance in Education, $19,208-223$.

Neary, M., Harrison, A., Crellin, G., Parekh, N., Saunders, G., Duggan, F.,Williams, S., \& Austin, A. (2010). Learning landscapes in higher education: Clearing pathways, making spaces, involving academics in the leadership, governance and management of academic spaces in higher education. Lincoln: Centre for Educational Research and Development Oblinger, D.G.(Ed). (2006). Learning space. Retrieved from http:// www.educause.edu 
Omar, F., Halim, F. W., Zainah, A. Z., Farhadi, H., Nasir, R., \& Khairudin, R. (2011). Stress and job

satisfaction as antecedents of workplace deviant behavior. World Applied Sciences Journal, 12, 45-51.

Parkin, J. K., Austin, S. A., Pinder, J. A., Baguley, T. S., \& Allenby, S.N. (2011). Balancing collaboration and privacy in academic workspaces. Facilities, 29, 31- 49.

Rytkönen, E. (2015). University campuses in spatial transformation. Facilities, 33, $794-818$.

Rytkönen, E., \& Nenonen, S. (2014). The Business Model Canvas in university campus management. Intelligent Buildings International, 6, 138-154.

Rytkönen, E., Nenonen, S., Österlund, E., \& Kojo, I. (2015). Process dynamics of managing interdisciplinary, crossorganizational learning campus in change. Facilities, 33, 752772.

State Council of Higher Education for Virginia (SCHEV) (2004), Space Utilization and Comparison Report. Retrieved from http:// www.schev.edu/Reportstats/2004SpaceUtilization ComparisonReport.pdf

Seddigh, A., Stenfors, C., Berntsson, E., Bååth, R., Sikstrőm, S., \& Westerlund, H. (2015). The association between office design and performance on demanding cognitive tasks. Journal of Environmental Psychology, 42, 172-181.

Unwin, S. D., Fecht, B.A., \& Bergsman, T. M. (2008). Business metrics of laboratory space utilization. Facilities, 26, $366-$ 373.

Wilding, M. (2012). End of an era mourned as DEGW rebrands. Retrieved April 10, 2016, from http://www.bdonline.co.uk/ end-of-an-era-mourned-as-degw-rebrands/5043293.article

Weiss, M. A., \& Schoenberger, E. (2015). Peter Hall and the western urban and regional collective at the University of California, Berkeley. Built Environment, 41, 63-77.

Worthington, J. (Ed.). (2006). Reinventing the workplace. Oxford: Elsevier. 
Appendix A

\section{RESEARCH LEARNING SPACE MODELS}

Please rank (from $1-5$, the scale given below) the learning workspace suitable for your work and learning activities

$1=$ very attractive, $2=$ attractive, $3=$ moderately attractive and $4=$ less attractive

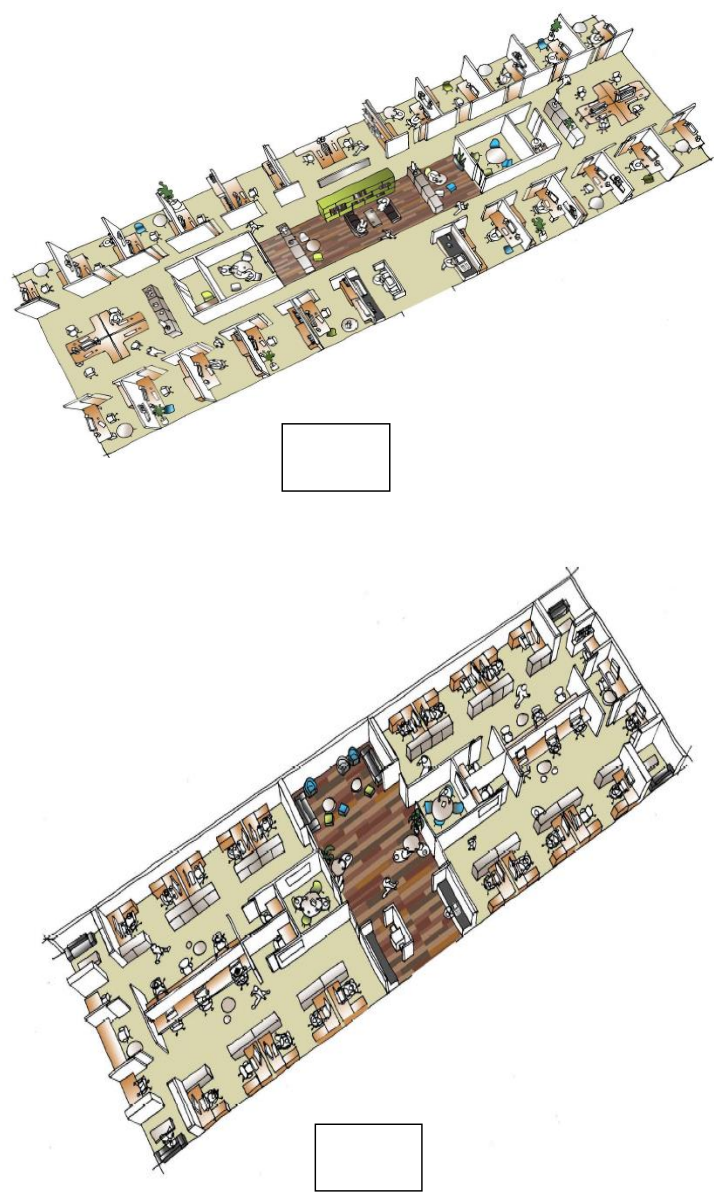

Please rank (from $1-5$, the scale given below) the learning workspace suitable for your work and learning activities

$1=$ very attractive, $2=$ attractive, $3=$ moderately attractive and 4=less attractive 


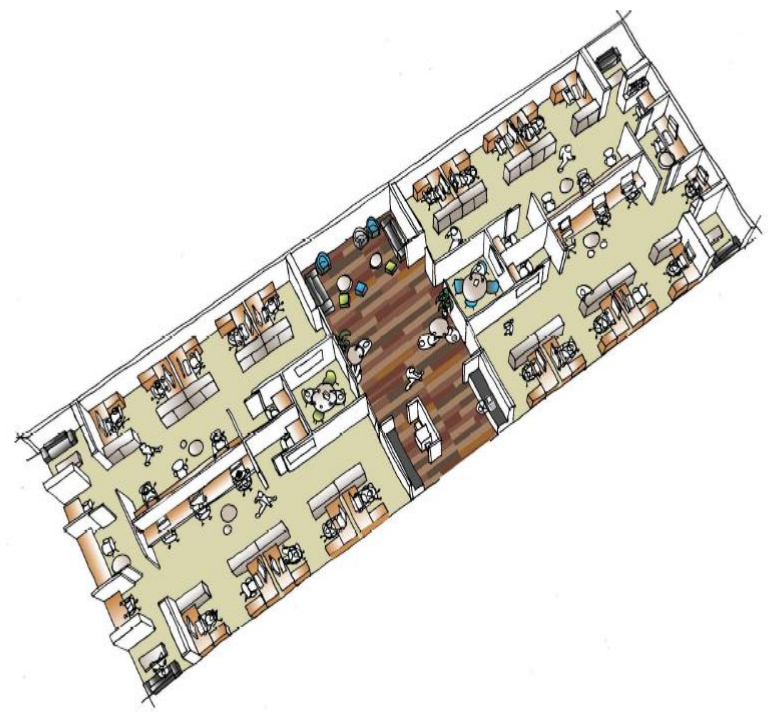

Please rank (from $1-5$, the scale given below) the learning workspace suitable for your work and learning activities

$1=$ very attractive, $2=$ attractive, $3=$ moderately attractive and $4=$ less attractive

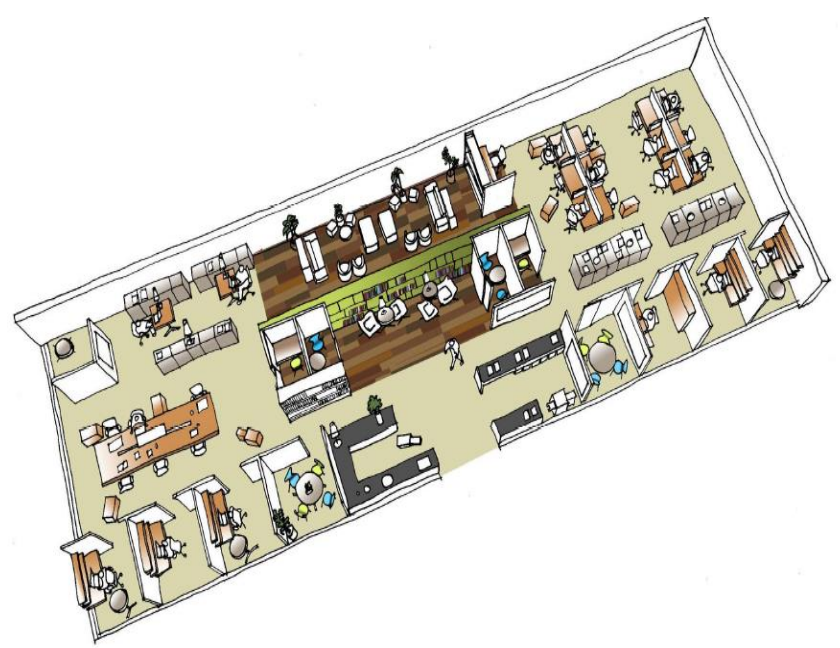

Please rank (from $1-5$, the scale given below) the learning workspace suitable for your work and learning activities

$1=$ very attractive, $2=$ attractive, $3=$ moderately attractive and $4=$ less attractive 


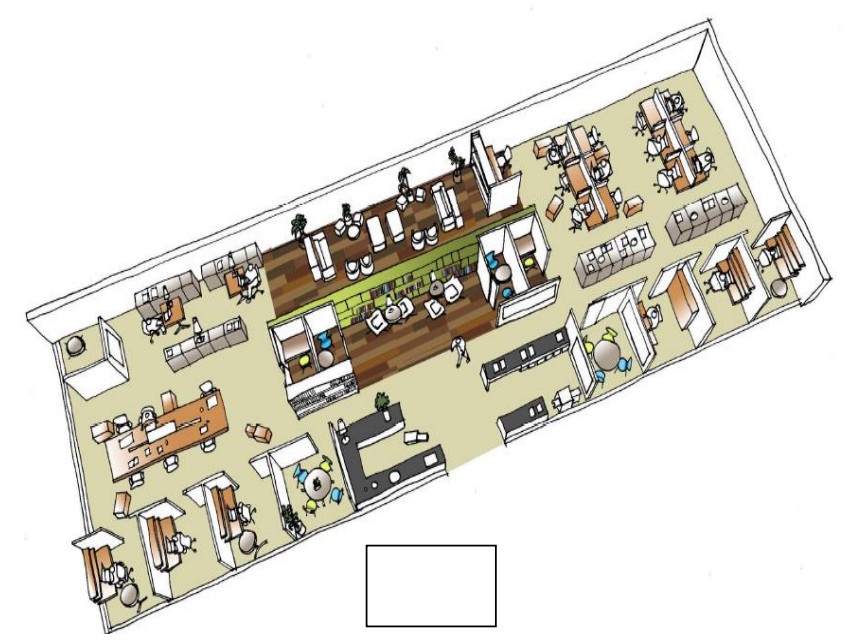

$1=$ very attractive, $2=$ attractive, $3=$ moderately attractive and $4=$ less attractive

Appendix B

Club Model

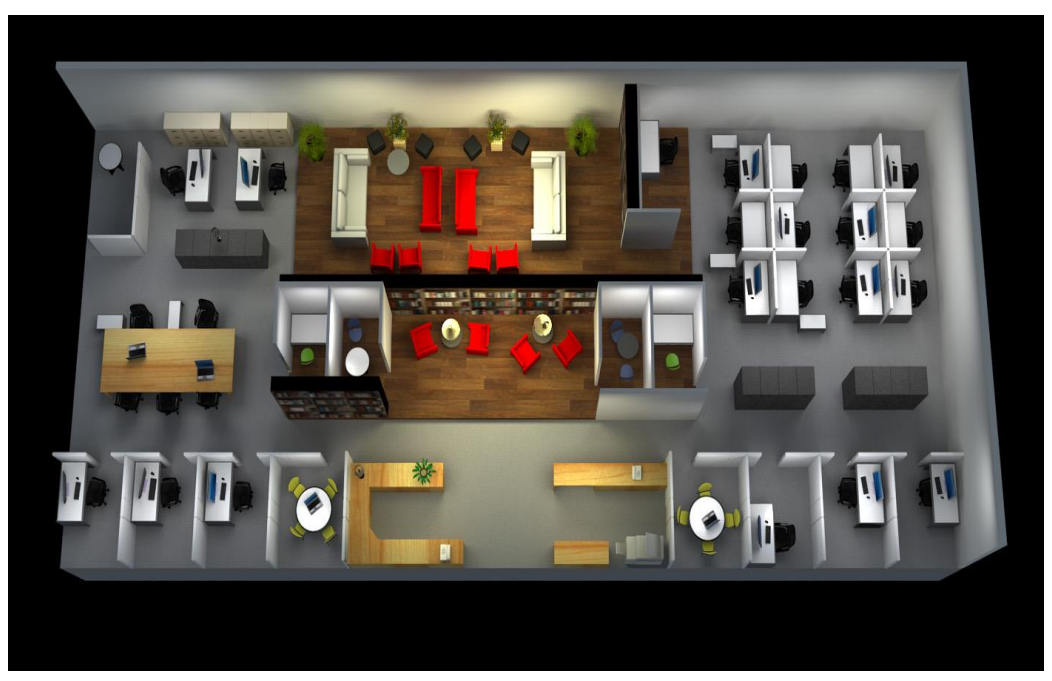

